University of Nebraska - Lincoln

DigitalCommons@University of Nebraska - Lincoln

USDA Forest Service / UNL Faculty Publications U.S. Department of Agriculture: Forest Service --

National Agroforestry Center

$3-2010$

\title{
A predictive model for detection of Agrilus planipennis (Col., Buprestidae) larvae in girdled ash (Fraxinus spp.)
}

\author{
J. M. Marshall \\ Michigan Technological University, Houghton
}

A. J. Storer

Michigan Technological University, Houghton

I. Fraser

Emerald Ash Borer Project, Brighton, MI

V. C. Mastro

Pest Survey, Detection, and Exclusion Laboratory, Otis ANGB, MA

Follow this and additional works at: https://digitalcommons.unl.edu/usdafsfacpub

Part of the Forest Sciences Commons

Marshall, J. M.; Storer, A. J.; Fraser, I.; and Mastro, V. C., "A predictive model for detection of Agrilus planipennis (Col., Buprestidae) larvae in girdled ash (Fraxinus spp.)" (2010). USDA Forest Service / UNL Faculty Publications. 153.

https://digitalcommons.unl.edu/usdafsfacpub/153

This Article is brought to you for free and open access by the U.S. Department of Agriculture: Forest Service -National Agroforestry Center at DigitalCommons@University of Nebraska - Lincoln. It has been accepted for inclusion in USDA Forest Service / UNL Faculty Publications by an authorized administrator of DigitalCommons@University of Nebraska - Lincoln. 


\title{
A predictive model for detection of Agrilus planipennis (Col., Buprestidae) larvae in girdled ash (Fraxinus spp.)
}

\author{
J. M. Marshall ${ }^{1}$, A. J. Storer ${ }^{1}$, I. Fraser $^{2}$ \& V. C. Mastro ${ }^{3}$ \\ 1 School of Forest Resources and Environmental Science, Michigan Technological University, Houghton, MI, USA \\ 2 USDA APHIS PPQ, Emerald Ash Borer Project, Brighton, MI, USA \\ 3 USDA APHIS PPQ, Pest Survey, Detection, and Exclusion Laboratory, Otis ANGB, MA, USA
}

\section{Keywords}

emerald ash borer, Fraxinus, invasive species

\section{Correspondence}

Jordan M. Marshall (corresponding author), Michigan Technological University, Cooperative Emerald Ash Borer Project, 5936 Ford Court, Suite 200, Brighton, MI 48116, USA. E-mail: jmmarsha@mtu.edu

Received: September 17, 2009; accepted: March 9, 2010.

doi: 10.1111/j.1439-0418.2010.01525.x

\begin{abstract}
Agrilus planipennis (emerald ash borer, Coleoptera: Buprestidae) is a pest of ash (Fraxinus spp.) in North America and has caused mortality of ash throughout its introduced range. One technique used for detection of A. planipennis is the establishment and peeling of girdled trap trees. In an effort to reduce the search effort and target detection survey efforts within ash trap trees, a predictive model was created using data from 2007 and validated using data from 2008. In 2007 and 2008, ash trap trees were established, harvested, peeled and inspected for A. planipennis larvae. Gaussian curves were fit to describe the relationship between stem diameter and relative proportion and frequency of larvae. The observed and predicted 2008 relative proportion and frequency of larvae did not differ in paired t-tests. Within the relative proportion and frequency Gaussian models, the curves peaked at approximately $10 \mathrm{~cm}$ diameter signifying the greatest proportion and frequency of A. planipennis larvae occurred at $10 \mathrm{~cm}$ stem diameter. This peak was then bracketed by $2 \mathrm{~cm}$ on each side creating a target stem section with a top diameter of $8 \mathrm{~cm}$ and a bottom diameter of $12 \mathrm{~cm}$. A simple linear regression was fit to describe the relationship between the larvae count within the targeted $8-12 \mathrm{~cm}$ section of tree and the larvae per $\mathrm{cm}^{3}$ of phloem per tree for 2007. The observed and predicted 2008 larvae per $\mathrm{cm}^{3}$ did not differ in a paired t-test. Targeting the $8-12 \mathrm{~cm}$ diameter section of the trap tree stem will reduce the amount of the tree peeled to less than $45 \%$ with more than $50 \%$ of $A$. planipennis larvae within the tree encountered in this targeted section. This reduction in the amount of tree peeled will greatly increase the number of trees and area surveyed for A. planipennis detection and population delimiting surveys.
\end{abstract}

\section{Introduction}

Agrilus planipennis Fairmaire (emerald ash borer, Coleoptera: Buprestidae) is an insect pest of North American ash (Fraxinus spp. L.) introduced from Asia (Haack et al. 2002; McCullough and Kotovich 2004). There is evidence that A. planipennis has been established in Michigan and Ontario, Canada since the mid-1990s, however it was not discovered until 2002 (Siegert et al. 2007). Subsequent populations have been identified in numerous other States and Provinces. Within its introduced range, A. planipennis has caused significant mortality of North American ash (Poland and Mcculough 2006; Poland 2007). Natural spread of this beetle does occur but establishment of satellite populations is greatly facilitated by human movement of ash wood products and ash nursery stock (Cappaert et al. 2005).

All species of North American ash are susceptible to infestation by A. planipennis and these species are 
more vulnerable than native Asian host trees when planted in the native range of $A$. planipennis and in planting bed experiments (Liu et al. 2003; Rebek et al. 2008). There is no evidence that other North American tree species are infested by A. planipennis (Anulewicz et al. 2006). This genus-specific vulnerability to $A$. planipennis has fueled concern for ash resources throughout North America in both rural and urban settings (Cappaert et al. 2005).

Larvae of A. planipennis feed on the phloem of ash trees from late summer to autumn and progress through four instars. Life history usually occurs as a progression through four instars in a single year, however, 2-year development does occur. Typically, larvae over-winter as pre-pupae within sapwood or bark chambers and pupate and emerge as adults in late spring, with variations in phenology corresponding to latitude and elevation (Bauer et al. 2004; McCullough and Kotovich 2004). Ash mortality is induced by phloem feeding larvae that inhibit nutrient movement by girdling the tree.

Detection efforts have focused on survey tools and techniques such as girdled ash trap trees, firewood inspections for signs, live tree inspections for symptoms and lured traps for adults (e.g. Cappaert et al. 2005; de Groot et al. 2006; Storer et al. 2007; Crook et al. 2008; Francese et al. 2008). As with most forest pests, without early detection, A. planipennis can become locally established, create new source populations for further dispersal and limit the effectiveness of early control efforts (Liebhold et al. 1995; USGAO 2006). The detection method that is considered the most effective utilizes girdled trap trees that are $100 \%$ peeled of bark, down to a minimum stem diameter, within a few months of the end of adult flight season. The peeling of these trees is time consuming and the results may be prone to false negatives. While targeting detection locations on high risk areas may reduce the cost of detection efforts for A. planipennis, it is important to focus detection efforts within the host tree to reduce detection costs. The objectives of this study were to identify a stem diameter range with the highest proportion of $A$. planipennis larvae, model the relationship between larval frequencies and stem diameter and validate the model with newly collected data.

\section{Materials and Methods}

\section{Data collection for model development}

Ash trap trees were established at 25 low density A. planipennis sites in Indiana (10), Michigan (14), and Ohio (one) during April and May 2007. Low density sites were identified as having A. planipennis present but with minimal ash mortality and trees exhibiting few signs and symptoms of infestation. At each site, two trap trees $(n=50)$ at least $30 \mathrm{~m}$ apart were selected and girdled within the same forest stand as part of a separate A. planipennis trapping study (Marshall et al. 2009a). Diameter at breast height (dbh, $1.37 \mathrm{~m}$ above soil surface) was measured for each tree. Trees were selected from available ash within forest stands, which included $F$. americana, F. nigra and F. pennsylvanica. Girdles were installed using a hand chainsaw to cut through the bark and phloem in two locations on the stem approximately $1 \mathrm{~m}$ above the ground and $1.25 \mathrm{~m}$ above the ground; the bark and phloem between these cuts were removed. Trap trees were harvested during November 2007-January 2008. Trees were stored at $4^{\circ} \mathrm{C}$ until peeled. All portions of each tree $\geq 5 \mathrm{~cm}$ in diameter were peeled and inspected for $A$. planipennis larvae, including pre-pupae in pupal chambers. Caliper diameter of the tree stem and stem height was measured for the location of each larva encountered. Stem height was used to calculate the percentage of each tree that was comprised of the target stem section with the greatest proportion and frequency of larvae.

\section{Data collection for model validation}

Ash trap trees were established at 60 low density sites as defined above; 22 for Indiana, 23 for Michigan, five for Ohio and 10 for Pennsylvania during April and May 2008. At each site, a single trap tree ( $\mathrm{n}=60$ ) was selected, dbh measured and girdled using a hand chainsaw as above as part of a separate A. planipennis trapping study (Marshall et al. 2009b). Trees were selected from available ash within forest stands, which included $F$. americana, $F$. nigra and F. pennsylvanica. Trap trees were harvested during November and December 2008. Trees were stored and peeled as above. Six sites that had been used in 2007 for model development were also used in 2008 for model validation; however, due to the destructive nature of the sampling, no individual trees were sampled in both years.

\section{Model development and validation}

t-tests were used to identify differences in the trap tree dbh and total larvae between sampling years. Pooling the data for all 2007 trees with A. planipennis larvae, we calculated the mean proportion and mean 
frequency of larvae that were found at each $1 \mathrm{~cm}$ diameter increment from $3-28 \mathrm{~cm}$. Relative proportion was calculated as the mean proportion at each $1 \mathrm{~cm}$ of diameter divided by the sum of mean proportions at all diameters $\left(\mathrm{p}_{i} / \Sigma \mathrm{p}_{i}\right.$, where $\mathrm{p}_{i}=$ mean proportion of larvae at $i$ th $\mathrm{cm}$ of diameter). Relative frequency was calculated as the mean frequency at each $1 \mathrm{~cm}$ of diameter divided by the sum of mean frequencies at all diameters $\left(\mathrm{f}_{i} / \Sigma \mathrm{f}_{i}\right.$, where $\mathrm{f}_{i}=$ mean frequency of larvae at $i$ th $\mathrm{cm}$ of diameter). Relative values were used to address the variability in A. planipennis population size across sites. Gaussian curves were used to characterize the relationships between the relative proportion and relative frequency of $A$. planipennis larvae (dependent) and the stem diameter (independent) for 2007 data. Residuals from the Gaussian curves were plotted vs. stem diameter and visually assessed for homoscedasticity (Zar 1999). The 2007 Gaussian curve equations were used to calculate predicted $A$. planipennis larval relative proportion and relative frequency for the observed 2008 diameters. Paired t-tests were used to test whether the mean predicted values were different from the observed values from the 2008 data. Correlation was used to test the relationships between the observed and predicted values.

Stem diameter values bracketing the peak of the Gaussian curves were selected for targeting larval detection within ash trees. The definite integral for the total curve, as well as for the target sections of the curve bracketing the peak, were calculated and used to calculate the percentage of the area under the curve composed of the targeted stem diameters. A t-test was used to test for differences in the percentage of larvae at instar stages within the target section of the tree and the entire tree. The relationship for the $\log$ transformed number of larvae for the target stem section and the log transformed larvae per $\mathrm{cm}^{3}$ of phloem for each tree (Eberhart 2007) was tested using simple linear regression. Volume of phloem was used to incorporate the thickness of phloem. Statistical analyses were performed at $\alpha=0.05$ with NCSS Statistical Software (ver. 2004).

\section{Results}

\section{Model development}

Twenty-two of the 50 trees peeled contained $A$. planipennis larvae and were used in the Gaussian curve model. These trap trees had a mean dbh of $14.36 \mathrm{~cm}$ (range: $10.2-20.1 \mathrm{~cm}$; SE: \pm 0.60 ) and contained a mean of 91.9 A. planipennis larvae
(SE: \pm 31.2 ). A significant Gaussian curve for relative proportion of larvae and stem diameter resulted from the analysis \{relative proportion of larvae $=0.09760$ $\times \exp \left[-0.5 \times(\right.$ diameter -10.00293$\left.) / 4.20145^{2}\right] ; \mathrm{F}=$ 62.693, $\mathrm{df}=3,18, \mathrm{P}<0.0001\} \quad$ (Fig. 1a). A similar Gaussian curve for relative frequency of larvae and stem diameter resulted from the analysis relative frequency of larvae $=0.09050 \times \exp [-0.5 \times($ diameter -10.77021$\left.) / 4.52211^{2}\right] ; F=100.928, d f=3,18$, $\mathrm{P}<0.0001\}$ (Fig. 1b). Both Gaussian curve equations had a residual mean of zero and were randomly distributed around zero (Fig. 2).

The main peak of the Gaussian curve for both the relative proportion and the relative frequency of larvae occurred in ash trees at approximately $10 \mathrm{~cm}$ stem diameter. A $2-\mathrm{cm}$ bracket on either side of $10 \mathrm{~cm}$ was selected as the target tree section (8$12 \mathrm{~cm}$ diameter). For both relative proportion and relative frequency of larvae, the area under the
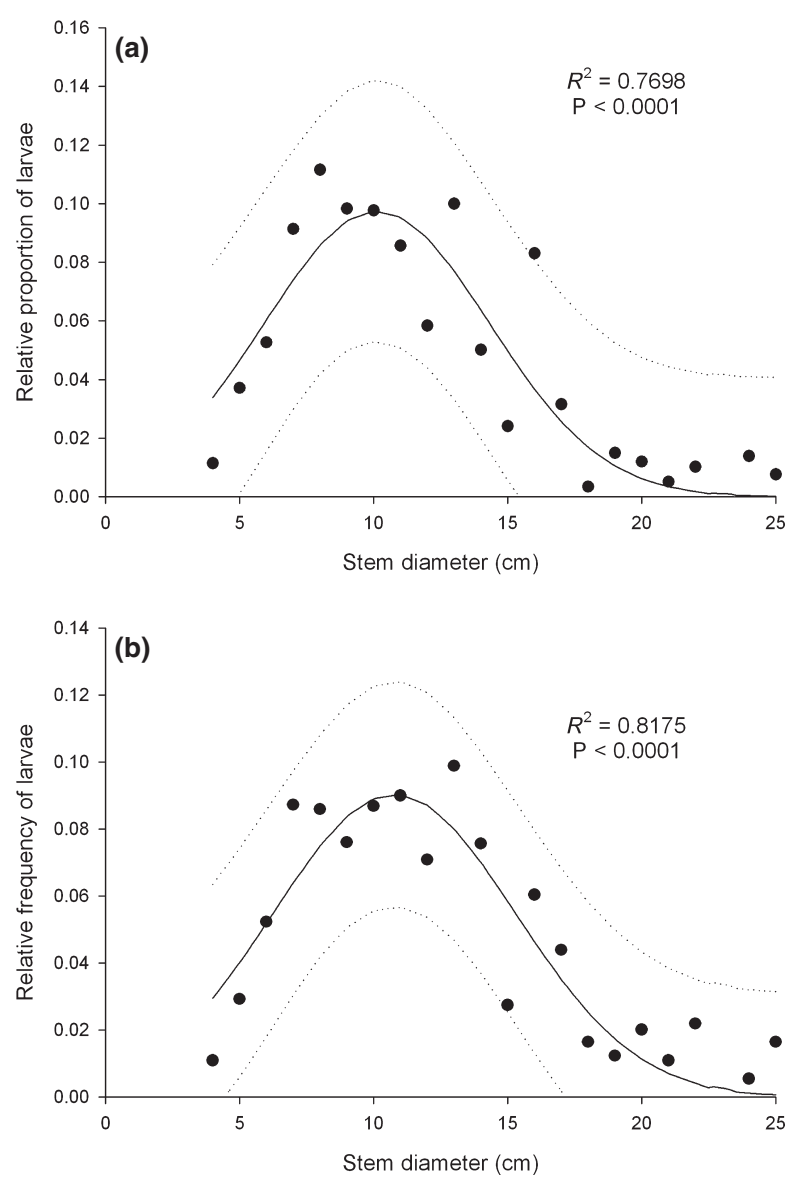

Fig. 1 Gaussian curves for (a) relative proportion and (b) relative frequency of Agrilus planipennis larvae locations for 2007 in ash trees related to stem diameter $(\mathrm{cm})$. Dotted lines indicate $95 \%$ confidence band. 


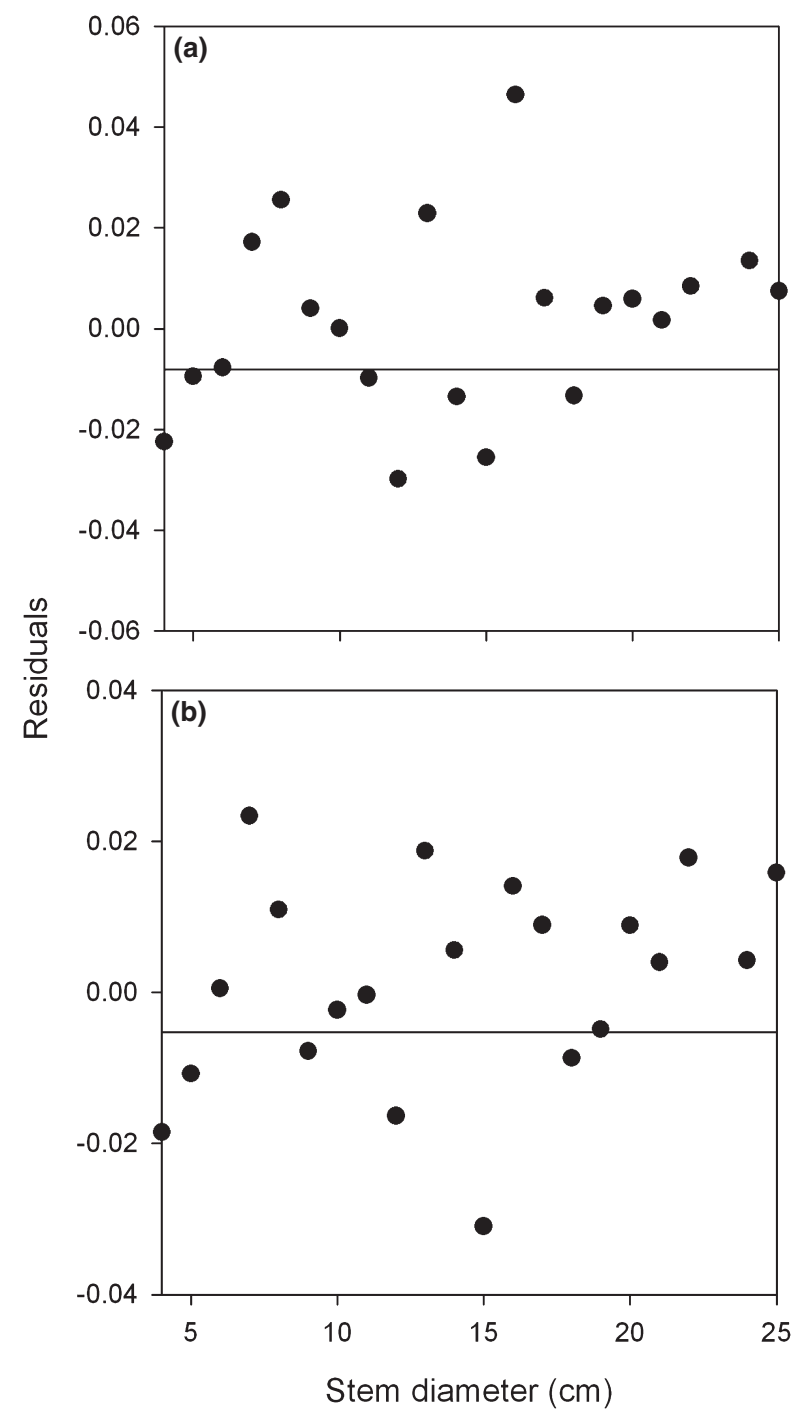

Fig. 2 Residual plots for Gaussian curve models describing the relationship between ash tree stem diameter and (a) relative proportion and (b) relative frequency of Agrilus planipennis larvae.

curve with a lower limit of $8 \mathrm{~cm}$ and upper limit of $12 \mathrm{~cm}$ accounts for $16.8 \%$ of the total area under the curve. While logs with these target diameters (a base of $12 \mathrm{~cm}$ and a top of $8 \mathrm{~cm}$ diameter) account for a mean of $44.7 \%$ (SE: \pm 2.3 ) of the stem length of each ash tree, they did account for $54.5 \%$ (SE: \pm 5.2 ) of the larvae within each tree. Also, $69.5 \%$ (SE: \pm 6.2 ) of the larvae occurring within the target tree section were three to four instar larvae or prepupae, which is not significantly different than the whole tree $[72.7 \%(\mathrm{SE}: \pm 5.4) ; \mathrm{t}=-1.309, \mathrm{df}=50$, $\mathrm{P}=0.2025]$. A significant simple linear relationship existed between the $\log$ transformed number of larvae within the targeted tree section and the log

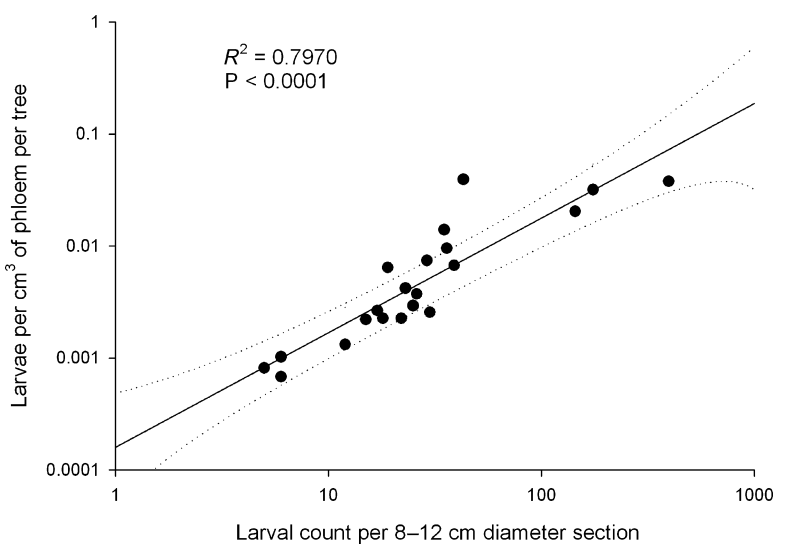

Fig. 3 Simple linear regression for larval count within ash tree stems at diameters $8-12 \mathrm{~cm}$ and larvae per $\mathrm{cm}^{3}$ of total phloem on the tree for 2007. Dotted lines indicate 95\% confidence band.

transformed larvae per $\mathrm{cm}^{3}$ of phloem per tree $(\log$ larvae per $\mathrm{cm}^{3}=-3.7979+1.0234 \times$ number of larvae, $\mathrm{R}^{2}=0.797, \mathrm{P}<0.0001$ ) (Fig. 3). All trees used to develop the model had larvae within the 8$12 \mathrm{~cm}$ diameter target section.

\section{Model validation}

Thirty of the 60 trees peeled contained A. planipennis larvae and were used in the validation of the 2007 Gaussian curve model. These trap trees had a mean $\mathrm{dbh}$ of $14.97 \mathrm{~cm}$ (range $10.8-31.1 \mathrm{~cm}$; SE: \pm 0.43 ), which was not significantly different from the 2007 trap trees $(\mathrm{t}=-0.860, \mathrm{df}=50, \mathrm{P}=0.3941)$. Also, the 2008 trap trees contained a mean of $161.1 \mathrm{~A}$. planipennis larvae (SE: \pm 39.6 ), which was not significantly different from the 2007 trap trees $(\mathrm{t}=-1.164$, $\mathrm{df}=50, \mathrm{P}=0.2499$ ).

Using the 2007 Gaussian curve equation, predicted values of relative proportion and relative frequency of larvae for 2008 observed diameters were calculated. The predicted relative proportion values were not significantly different from the paired observed 2008 values $(\mathrm{t}=0.132, \mathrm{df}=40, \mathrm{P}=0.8963)$. Also, the predicted relative frequency values were not significantly different from the paired observed 2008 values $(\mathrm{t}=0.180, \mathrm{df}=40, \mathrm{P}=0.8587)$. For both relative proportion and frequency, the observed and predicted values were significantly correlated (Fig. 4 $a$ and b). Using the 2007 simple linear regression model, the predicted larvae per $\mathrm{cm}^{3}$ of phloem per tree for 2008 observed larvae within the targeted stem diameters $(8-12 \mathrm{~cm})$ were calculated. The predicted values of larvae per $\mathrm{cm}^{3}$ of phloem were not significantly different from the paired observed 2008 

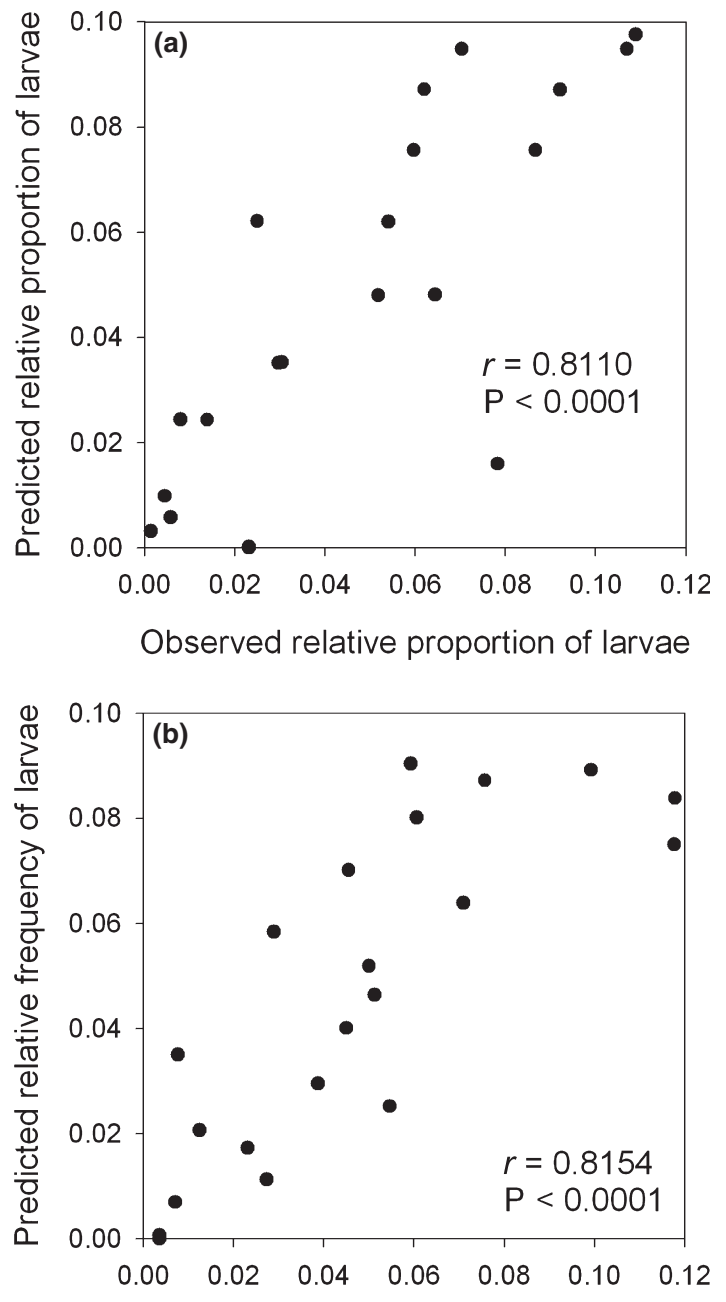

Observed relative frequency of larvae

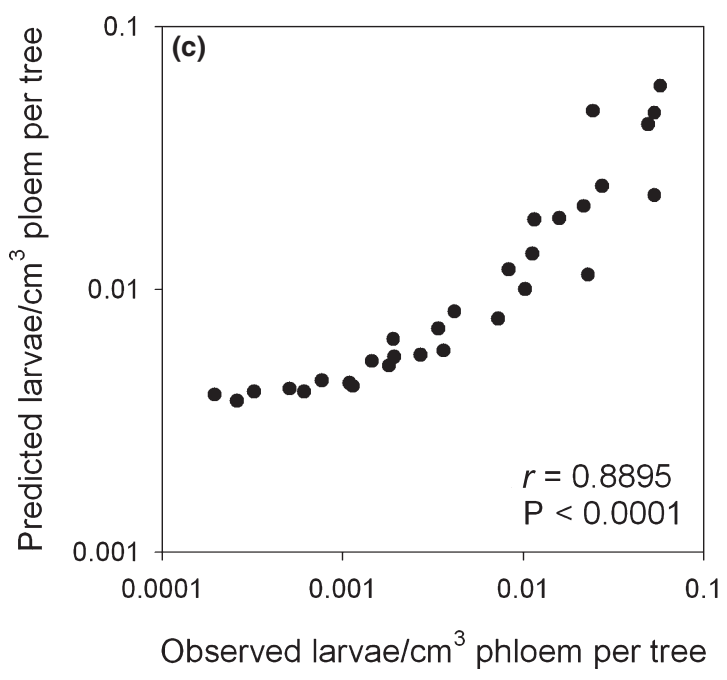

Fig. 4 Correlation scatter plots for (a) relative proportion, (b) relative frequency and (c) density of Agrilus planipennis larvae observed and predicted values. values $(\mathrm{t}=-0.896, \mathrm{df}=58, \mathrm{P}=0.3777)$. Also, the observed and predicted values of larvae per $\mathrm{cm}^{3}$ of phloem per tree were significantly correlated (Fig. 4c). One tree from 2008 did not have larvae within the $8-12 \mathrm{~cm}$ diameter target section; however that tree contained only four larvae in total.

\section{Discussion}

Using ash trap trees for the detection of A. planipennis is a labour intensive and time consuming technique. It is, however, a strategy employed by several States, Provinces and other government agencies. The results presented here suggest that by targeting detection efforts within a specific section of a trap tree, between 8 and $12 \mathrm{~cm}$ diameter, the search effort of field crews can be greatly reduced due to the need to peel less than $50 \%$ of the trap tree. Also, A. planipennis larvae within that specific section of an ash tree can act as a surrogate for the density of larvae in the entire tree. In both detection and population delimiting surveys, limiting the portion of the trap tree that is actually peeled increases the rate at which trees can be inspected, as well as provide density information regarding the population in question.

The Gaussian curve from the 2007 data provided a strong description of the relationship between stem diameter and the relative proportion and relative frequency of $A$. planipennis larvae within ash trees. The main peak created by this curve equation provides a targeted diameter of the ash tree stem to find the greatest proportion and frequency of larvae. Also, if A. planipennis has infested an ash tree, there is a very high likelihood that it will be detected within the target section between 8 and $12 \mathrm{~cm}$ diameter. The range of $8-12 \mathrm{~cm}$ diameter includes the $8-10 \mathrm{~cm}$ diameter of peak larval density in young green ash trees presented by Timms et al. (2006) from sites that may have been more heavily infested than those used in this study. The addition of a $2-\mathrm{cm}$ bracket on either side of that $10 \mathrm{~cm}$ diameter peak is an effort to increase the search area while minimizing the odds of a false-negative survey. Increasing the target diameter range to $7 \mathrm{~cm}$ top and/or $13 \mathrm{~cm}$ base increases the amount of the tree needing to be peeled while increasing the proportion of larvae within the tree encountered by $5 \%$. By targeting the 8-12 cm diameter section of ash trap trees, detection survey crews can peel less than $45 \%$ of a single tree and have the ability to encounter over $54 \%$ of the larvae within that tree. This technique provides a suitable alternative to peeling the entire tree. In detection and delimiting survey programs, it is typi- 
cal for field crews to peel until larvae are encountered. By beginning within the $8-12 \mathrm{~cm}$ diameter targeted section of an ash tree, these crews can increase the odds of detection in a shorter period of time. Although one tree from 2008 did not contain larvae within this $8-12 \mathrm{~cm}$ diameter section, using a single tree within an ash stand would not be recommended for a survey programme even if an entire tree peel was utilized.

The lack of difference between the 2007 and 2008 trap trees for dbh and larval density signify the suitability of the 2008 data set for validating the 2007 model. Similar tree size resulted in similar resource availability (i.e. phloem volume) for A. planipennis larvae. Comparing the 2008 observed with the 2008 predicted values of $A$. planipennis paired by diameter resulted in no significant difference for larval relative proportion or relative frequency, as well as significant positive correlations. While there was variation in the predicted and observed values, as would be expected, this was minimal and resulted in a precise and accurate prediction of the 2008 relative proportions and relative frequencies of larvae.

In addition to the models predicting the location of larvae within the tree, the simple linear regression equation provides a valid prediction of A. planipennis larval density within ash trees. The predicted 2008 larvae per $\mathrm{cm}^{3}$ of phloem did not differ from the observed 2008 values. While targeting A. planipennis detection within the $8-12 \mathrm{~cm}$ diameter section of stem can decrease the amount of time used in a detection survey, the larval counts from that section can be used to assess the density of A. planipennis larvae within the entire tree. It is important to note that since the models were constructed using data from girdled ash trees, there may be limitations to predicting the $A$. planipennis density at the site or stand level. However, Marshall et al. (2009) have demonstrated that larval densities within girdled and ungirdled ash trees do not differ.

These predictive models do not provide targeting within a stand or forest for detection of A. planipennis. Incorporating other targeting techniques may add to the increased survey efficiency of targeting within a single tree, such as focusing on locations with likely human-assisted dispersal (i.e. campgrounds), incorporating canopy assessments to identify declining ash trees and taking into consideration site and environmental characteristics (i.e. ash trees in drier soils and under stress may be more susceptible to A. planipennis). These models do provide targeting within trap trees set in a detection programme or delimiting survey. With the growing range of A. planipennis within North America, improved detection tools will have a direct effect on the management of this pest. By decreasing the time needed for peeling trap trees, more area can be covered in detection and population delimiting surveys. Once a clearly delimited population is defined, application of various silvicultural, biological and chemical management tools can be more precise.

\section{Acknowledgements}

The authors would like to thank John DeLisle, Rob Miller, Michael Rietz and Nicole Smith for assistance in harvesting and peeling trap trees, as well as Rita Koch and Janet Oisten for assistance in site selection and trap tree establishment and Robert Froese and Robert Keen for statistical analysis consultation. Funding for this research was provided by the USDA APHIS Accelerated EAB Research Program. We would also like to thank the anonymous reviewers for their much appreciated comments and suggestions.

\section{References}

Anulewicz AC, McCullough DG, Miller DL, 2006. Oviposition and development of emerald ash borer (Agrilus planipennis) (Coleoptera: Buprestidae) on hosts and potential hosts in no-choice bioassays. Great Lakes Entomol. 39, 99-112.

Bauer LS, Haack RA, Miller DL, Petrice TR, Liu H, 2004. Emerald ash borer life cycle. In: Emerald ash borer research and technology meeting. FHTET-2004-02. Comp. by Mastro V, Reardon R, Forest Health Technology Enterprise Team, Morgantown, WV, 8.

Cappaert D, McCullough DG, Poland TM, Siegert NW, 2005. Emerald ash borer in North America: a research and regulatory challenge. Am. Entomol. 51, 152-165.

Crook DJ, Khrimian A, Francese JA, Fraser I, Poland TM, Sawyer AJ, Mastro VC, 2008. Development of a hostbased semiochemical lure for trapping emerald ash borer Agrilus planipennis (Coleoptera: Buprestidae). Environ. Entomol. 37, 356-365.

Eberhart TL, 2007. Emerald ash borer: host preferences of a newly established population and development of silvicultural management tools. MS Thesis, Michigan Technological University.

Francese JA, Oliver JB, Fraser I, Lance DR, Youssef N, Sawyer AJ, Mastro VC, 2008. Influence of trap placement and design on capture of the emerald ash borer (Coleoptera: Buprestidae). J. Econ. Entomol. 101, 1831-1837.

de Groot P, Biggs WD, Lyons DB, Scarr T, Czerwinski E, Evans HJ, Ingram W, Marchant K, 2006. A visual 
guide to detecting emerald ash borer damage. Natural Resources Canada, Great Lakes Forestry Center, Sault Ste. Marie, Ontario.

Liebhold AM, Macdonald WL, Bergdahl D, Mastro VC, 1995. Invasion by exotic forest pests: a threat to forest ecosystems. Forest Sci. Monographs 30, 1-58.

Liu H, Bauer LS, Gao R, Zhao T, Petrice TR, Haack RA, 2003. Exploratory survey for the emerald ash borer, Agrilus planipennis (Coleoptera: Buprestidae), and its natural enemies in China. Great Lakes Entomol. 36, 191-204.

Marshall JM, Storer AJ, Fraser I, Beachy JA, Mastro VC, 2009a. Effectiveness of differing trap types for the detection of emerald ash borer (Coleoptera: Buprestidae). Environ. Entomol. 38, 1226-1234.

Marshall JM, Storer AJ, Fraser I, Mastro VC, 2009b. Efficacy of trap and lure types for detection of Agrilus planipennis (Col., Buprestidae). J. Appl. Entomol. doi: 10.1111/j.1439-0417.2009.01455.x .

McCullough DG, Kotovich SA, 2004. Pest alert. Emerald ash borer. NA-PR-02-04, USDA, Forest Service, Northeastern Area, Newton Square, PA.

Poland TM, 2007. Twenty million ash trees later: current status of emerald ash borer in Michigan. Newsletter Mich. Entomol. Soc. 52, 10-14.
Poland TM, Mcculough DG, 2006. Emerald ash borer: invasion of the urban forest and the threat to North America's ash resource. J. Forestry 104, 118-124.

Rebek EJ, Herms DA, Smitley DR, 2008. Interspecific variation in resistance to emerald ash borer (Coleoptera: Buprestidae) among North American and Asian ash (Fraxinus spp.). Environ. Entomol. 37, 242-246.

Storer AJ, Metzger JA, Heyd RL, Katovich SA, Hyslop MD, 2007. Three years of a risk-based emerald ash borer detection survey and firewood survey in Michigan and Wisconsin. In: Emerald ash borer and Asian longhorned beetle research and technology development meeting. FHTET-2007-04. Comp. by Mastro V, Lance D, Reardon R, Parra G, Forest Health Technology Enterprise Team, Morgantown, WV, 70-71 .

Timms LL, Smith SM, de Groot P, 2006. Patterns in the within-tree distribution of the emerald ash borer Agrilus planipennis (Fairmaire) in young, green-ash plantations of south-western Ontario, Canada. Ag. Forest Entomol. 8, 313-321.

USGAO, 2006. Invasive forest pests: lessons learned from three recent infestations may aid in managing future efforts. USGAO, GAO-06-353, Washington, DC. 